\title{
Caries Incidence in Children of Primorsko Goranska County, Croatia
}

\author{
Bakarcic $\mathrm{D}^{1}$, Ivancic Jokic $\mathrm{N}^{1}$, Perkovic $\mathrm{I}^{2}$, Hrvatin $\mathrm{S}^{3}$, Glibotic Kresina $\mathrm{H}^{4}$, Kresina $\mathrm{S}^{5}$, \\ Negovetic Vranic $\mathrm{D}^{6^{*}}$ and Verzak $\mathrm{Z}^{6}$ \\ ${ }^{1}$ Professor, Department of Paediatric Dentistry, Faculty of Medicine of the University of Rijeka, Clinical Hospital Center Rijeka, \\ Croatia \\ ${ }^{2}$ Doctor, Faculty of Medicine of the University of Rijeka, Croatia \\ ${ }^{3}$ Doctor, Department of Paediatric Dentistry, Faculty of Medicine of the University of Rijeka, Clinical Hospital Center Rijeka, \\ Croatia \\ ${ }^{4}$ Doctor, Department of Social medicine and Epidemiology, Faculty of Medicine of the University of Rijeka, Teaching Instinute \\ of Public health of Primorsko-goranska County, Croatia \\ ${ }^{5}$ Doctor, Department of School and University medicine, Teaching Instinute of Public health of Primorsko-goranska County, \\ Croatia \\ ${ }^{6}$ Professor, Department of Paediatric Dentistry Dental School University of Zagreb, Clinical Department of Paediatric \\ Dentistry, Clinical Hospital Center Zagreb, Croatia
}

*Corresponding author: Negovetic Vranic D, School of Dental Medicine University of Zagreb, Department of Paediatric dentistry at University Hospital Zagreb, Gundulićeva 5, 10000 Zagreb, Croatia, Tel: 0038514802110 , E-mail: dnegovetic@sfzg.hr

Citation: Bakarcic D, Ivancic Jokic N, Perkovic I, Hrvatin S, Glibotic Kresina H, et al. (2017) Caries Incidence in Children of Primorsko Goranska County, Croatia. J Oral Health Dent Sci 2: 101

Article history: Received: 08 November 2017, Accepted: 22 January 2018, Published: 24 January 2018

\section{Abstract}

Introduction: The aim of this study was to investigate the incidence of caries in a 6-year follow-up study, to determine the Treatment Needs Index for dental caries, and the restorative Care Index.

Methods: The study included all schoolchildren from PGC aged six years in 2008. Later, in 2014, those same children were examined again at the age of twelve. There were included 1369 children, 630 girls and 739 boys. The clinical examination was carried out by one skilled examiner helped by assistant through a 3 month period during the academic years 2008 and 2014.

Results: Seventy four percent of six years olds presented with caries as opposed to later examination at the age of twelve in which $59 \%$ of the children presented caries experience. The mean dft index in the 6 years period decreased from 4.79 (SD $\pm 4,85)$ to 1,08 (SD $\pm 1,72$ ). Treatment Needs Index for primary theeth at the age of 6 and 12 years were $76.07 \%$ and $81.13 \%$ respectively.Care Index of primary teeth at six years olds showed only $20 \%$ of treated teeth and in twelve years olds $22 \%$.

Conclusion: Caries incidence shown by mean DMFT/dft index has increased in period of six years between two examinations. Inversely, it was observed an increase of the caries free children at the level of permanent dentition. This indicates only increased awareness of the importance of care about permanent teeth. Indices indicating the level of dental care are not satisfactory.

Keywords: Incidence; Caries; Children; Croatia

\section{Introduction}

Oral health is an important component of general health. It has an impact on quality of life because, e.g. dental caries can influence on a person's ability to eat, speak or socialise [1]. The incidence of dental caries in children is often related to the lifestyle of every individual. Incidence shows the rate of newly diagnosed cases of the disease. Generally, it is reported as the number of new cases occurred within a period of time [2-5]. Today caries is still a very significant public health problem and one of the most common diseases in children [6-8].

In the last 20-30 years significant improvements in children's oral health are made in many developed countries [5-10]. During this last decade the experts agreed that caries activity is statistically declined in the population and continues to decline. Significant efforts are done to achieve a reduction in cavities in organized societies, including the: use of systemic and topical fluoridation, 
improvements in diet counselling, oral health education and care for oral health in general which resulted in the decline of caries activity [5-11].

On the other hand, the results show that the growth of caries activity can be seen in less developed societies, immigrants and children. Unfortunately, the benefits of prevention programs have not yet reached those groups [9-11].

According to the World Health Organization (WHO) great importance is given to six year olds and twelve year olds. Six years old children represent a relevant group for caries assessment at the level of primary dentition, which shows greater variation in a shorter span of time, while twelve year olds represent a relevant group for permanent dentition due to presence of all permanent teeth except the third molars. This group is relevant for caries assessment in the permanent dentition [12,13]. Also at the age of six are mostly present first permanent molars, which are very important for the further development of the dentition. In addition, twelve year olds are taken into account as the default age of global studies and international comparisons of movement of oral cavity diseases. Well processed oral health data are the basis for planning and implementation of health policies in all countries [12-14].

The aim of this study was to investigate the incidence of caries in a 6-year follow-up study, to determine the Treatment Needs Index (TNI) for dental caries, and the restorative Care Index (CI), among children in Primorsko Goranska County (PGC), Croatia.

\section{Materials and Methods}

The study included all schoolchildren from PGC aged six years in 2008. Later, in 2014, those same children were examined again at the age of twelve since they still attended same school so were available for exam. There were included 1369 children, 630 girls and 739 boys. The clinical examination was carried out by same skilled examiner helped by assistant through a 3 month period during the academic years 2008 and 2014 at participating schools in the County.All participants gave verbal consent and the consent procedure was approved by the ethics committee/institutional review board. This research was conducted in full accordance with the World Medical Association Declaration of Helsinki and approved by the Ethics Committee of the Faculty of Medicine of the University of Rijeka, Croatia and was conducted during the academic year 2008/2014.

The examination was carried out by the " lift the lip " technique. For indirect view of lingual and palatal teeth surfaces single use mouth mirrors were used. For lighting, the head lamp was used. Caries was recorded according to WHO criteria, only if there was a visible evidence of tooth cavitation. DMFT index and dft index were assessed. To obtain further results, other indices such as TNI and CI were used. They were derived and calculated from the underlying DMFT and dft index [15-18].

Statistical analyses were carried out using SPSS Version 17.0 (SPSS Inc., Chicago, IL, USA).

\section{Results}

Results of this study showed that $74 \%$ of six years olds presented with caries as opposed to later examination at the age of twelve in which $59 \%$ of the children presented caries experience. A significant increase in caries free children is shown. Based on a review of all the teeth examined in different periods, values of dft and DMFT index were calculated. Based on those values TNI and CI were assessed. The value of the mean dft index in the 6 years period decreased from $4.79(\mathrm{SD} \pm 4,85)$ to $1,08(\mathrm{SD} \pm 1,72)$, which is logical because of the very few remaining primary teeth at the age of twelve. On the other hand, the value of the mean DMFT increased from $0,21(\mathrm{SD} \pm 0,67)$ to $1,27(\mathrm{SD} \pm 1,72)$ which is supported by the increased number of permanent teeth in twelve years old and their longer presence in the oral cavity.

\section{Discussion}

In a similar Swiss study, a slight increase in the mean DMFT index was seen among children of Swiss nationality and origin. The value increased from 0,12 to 0,73 , but in children of immigrant origin increase was even greater, it was from 0,21 to 1,27 as identical value to our DMFT index [19]. Such results were to be expected because these immigrants at that time originated from our territories, the Balkans, but now they come more from the Middle East. Similar dft values were presented in study from Georgia but for DMFT was reported some worse results of 2.04 [20]. Better results for dft were shown in a Greek study, but the same study presents DMFT of 1.35 [21]. A similar increase is present in certain Italian study [22]. The drop of DMFT values was reported by some other studies from: Scotland, Ireland, Poland and Finland. They attributed this decrease to intensive and high-quality prevention programs [23-26]. TNI index for primary teeth shows that at age of six years there were $76.07 \%$ of untreated teeth, and at age of twelve years olds this ratio changed in favour of untreated teeth, up to $81.13 \%$. In permanent teeth the situation is much better, at age of six there was $66.66 \%$ of untreated primary teeth except first molar, hence $2 / 3$. In twelve year olds, $2 / 3$ were treated (32.20\%), this shows greater concern for the permanent teeth in the six years olds but especially in twelve years old. CI of primary teeth at six years olds shows that only $20 \%$ of the teeth were treated while in 12 years old $22 \%$ of the teeth that needed tratment were restored. The $80 \%$ and $78 \%$ of untrated teeth among 6 and 12 years olds respectively remained untreated. These points to extremely poor dental care for primary teeth. In permanent teeth of six years olds $42 \%$ was treated, while in twelve years olds $70 \%$ of the teeth were treated. This is not surprising because dentists can manage those children easier than the small ones Figure (1,2,3 and 4).

They are usually less cooperative and sometimes unexperienced dentist are not as successful in working with small children as experienced trained dentists. From this data it can be concluded that public health have large impact, in this case the field of dental medicine and prevention programs. This impact on the incidence of dental caries in children can be perceived through the 
years of work in kindergartens, schools and educational institutions in general. Contact with information on oral health and the preservation of oral hygiene at an early age is very important for the child development and later the society as a whole [27,28].

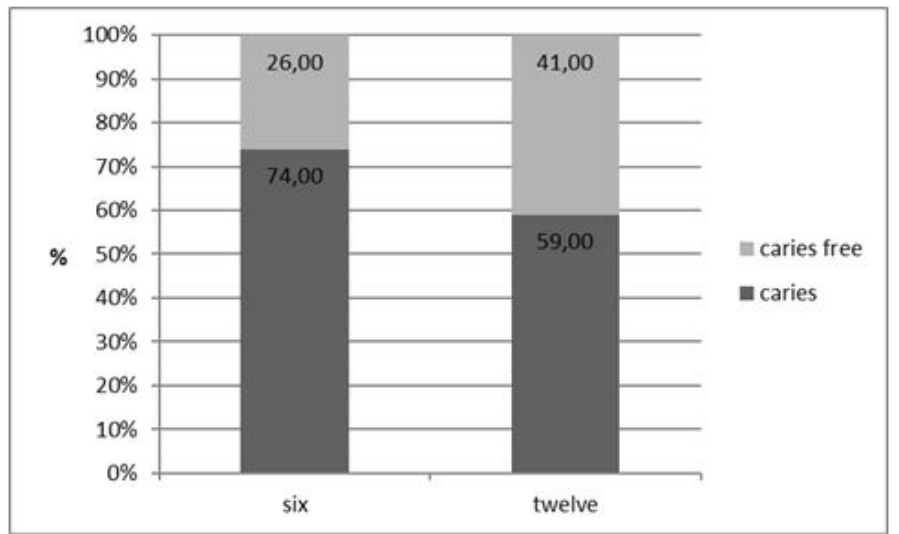

Figure 1: Percentage of children affected by caries

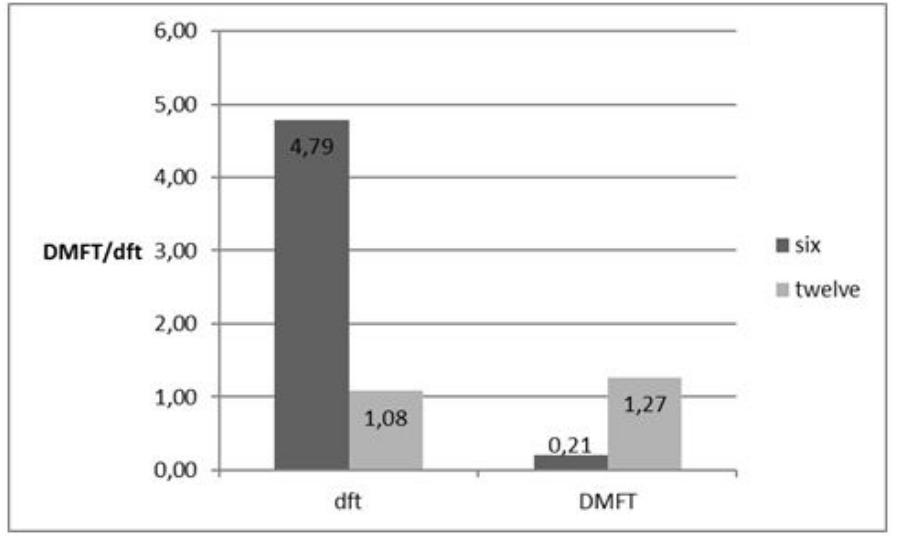

Figure 2: DMFT and dft values comparison

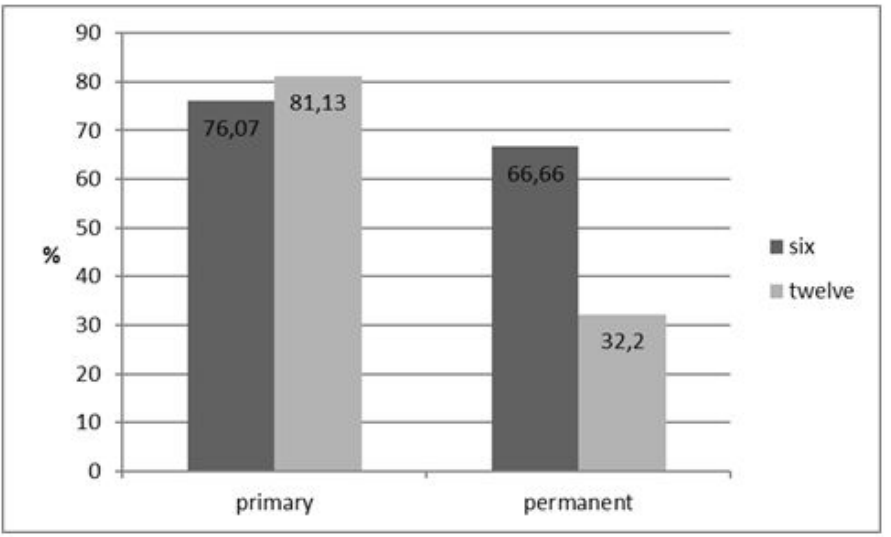

Figure 3: TNI values comparison

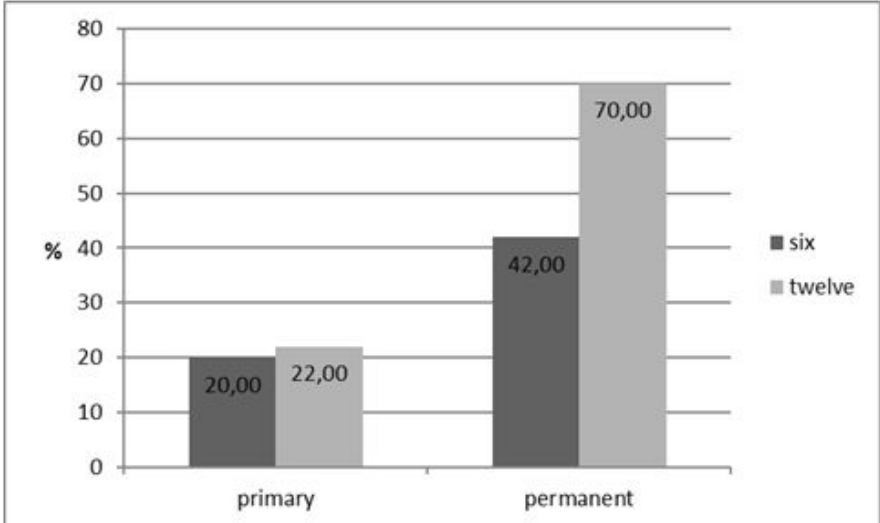

Figure 4: Treated teeth percentage comparison (CI) 


\section{Conclusions}

Caries incidence shown by mean DMFT/dft index has increased in period of six years between two examinations. Inversely, it was observed an increase of the caries free children at the level of permanent dentition. This indicates only increased awareness of the importance of care about permanent teeth. Indices indicating the levels of dental care are not satisfactory and there should be stronger public health initiatives and increased access to care through education.

\section{References}

1. National Advisory Committee on Oral Health (2004) Healthy mouths healthy lives: Australia's National Oral Health Plan 2004-2013. Adelaide, SA: South Australian Department of Health 2004.

2. Waning B, Montagne M (2001) Chapter 2. Medical Surveillance and Outbreaks of Disease. In: Waning B, Montagne M, eds. Pharmacoepidemiology: Principles and Practice. New York: McGraw-Hill.

3. Walters RW, Kier KL (2012) Chapter 8. The Application of Statistical Analysis in the Biomedical Sciences. In: Kier KL, Malone PM, Stanovich JE, eds. Drug Information: A Guide for Pharmacists ( $4^{\text {th }}$ edn) New York: McGraw-Hill.

4. Greenberg RS, Daniels SR, Flanders WD, Eley JW, Boring JR (2005) Chapter 2. Epidemiologic Measures. In: Greenberg RS, Daniels SR, Flanders WD, Eley JW, Boring JR, eds. Medical Epidemiology. ( $4^{\text {th }}$ edn) New York: McGraw-Hill.

5. Frazao P (2012) Epidemiology of dental caries: when structure and context matter. Braz Oral Res 1: 108-14.

6. Teixeira AK, Roncalli AG, Noro LR (2016) Factors related to the dental caries incidence in youth: a cohort study in Brazilian Northeastern. Cien Saude Colet 21: 3871-8.

7. Jurić H, Klarić T, Lulić-Dukić O (2003) Caries in children with regard to oral hygiene habits and previous caries experience. (Pojavnost karijesa u djece s obzirom na oralno-higijenske navike i prijašnje karijes iskustvo). Acta stomatologica Croatica 37: 340-1.

8. Anderson M (2002) Risk assessment and epidemiology of dental caries: review of the literature. Pediatr Dent 24: 377-85.

9. Harris R, Nicoll AD, Adair PM, Pine CM (2004) Risk factors for dental caries in young children: a systematic review of the literature. Community Dent Health 21: 71-85.

10. Marthaler TM (2004) Changes in Dental Caries 1953-2003. Caries Res 38: 173-81.

11. Bagramian RA, Garcia-Godoy F, Volpe AR (2009) The global increase in dental caries. A pending public health crisis. Am J Dent 21: 3-8.

12. Petersen PE (2003) The World Oral Health Report 2003: continuous improvement of oral health in $21^{\text {st }}$ century - the approach of the WHO Global Oral Health Programme. Community Dent Oral Epidemiol 1: 3-24.

13. Petersen PE (2005) Priorities for research for oral health in the $21^{\text {st }}$ century - the approach of the WHO Global Oral Health Programme. Community Dent Oral Epidemiol 22: 71-4.

14. Fejerskov O, Kidd E (2003) Dental Caries. The disease and its clinical management. Blackwell Munksgaard.

15. WHO (2013) Oral health surveys: basic methods $-\left(5^{\text {th }}\right.$ edn).

16. García-Cortés JO, Medina-Solís CE, Loyola-Rodriguez JP, Mejía-Cruz JA, Medina-Cerda E, et al. (2009) Dental caries' experience, prevalence and severity in Mexican adolescents and young adults. Rev Salud Publica 11: 82-91.

17. Mann J, Sgan-Cohen HD, Asher RS, Amir E, Cohen S, Sarnat H (1993) A treatment need index: a pilot study. Int J Paediatr Dent 3: 129-34.

18. Medina-Solis CE, Pontigo-Loyola AP, Mendoza-Rodríguez M, Lucas-Rincón SE, Márquez-Rodríguez S (2013) Treatment Needs for Dental Caries, Restorative Care Index, and Index of Extractions in Adolescents 12 and 15 Years Old. West Indian Med J 62: 636-41.

19. Waltimo T, Menghini G, Weber C, Kulik EM, Schild S, et al. (2016) Caries experience in 7-, 12-, and 15-year-old schoolchildren in the canton of BaselLandschaft, Switzerland, from 1992 to 2011. Community Dent Oral Epidemiol 44: 201-8.

20. Sagan-Cohen HD, Margvelashvili V, Bilder L, Kalandadze M, Gordon M, et al. (2014) Dental caries among children in Georgia by age, gender, residence location and ethnic group. Community Dent Health 31: 1-4.

21. Gatou T, Kounari HK, Mamai-Homata E (2011) Dental caries prevalence and treatment needs of 5 to 12 -year-old children in relation to area-based income and immigrant background in Greece. International Dent J 61: 144-51.

22. Brambilla E, Toselli A, Felloni A, Gagliani M (1997) The effect of biannual applications of amine fluoride solution on caries incidence in permanent first molars: a 5-year study. Int J Paediatr Dent 7: 9-14.

23. Formby M (2015) Effective caries prevention in a hebridean island population. Prim Dent J 4: 27-32.

24. Vrbič V (2014) Zobno zdravje PRI 12 letni mladini v Sloveniji (1987 - 2013). Zobozdrav Vestn 69: 74-80.

25. Emerich K, Adamowicz-Klepalska B (2010) Trends in dental caries experience among children and adolescents in northern Poland between 1995 and 2003. Community Dent Health 27: 218-1.

26. Luoma AR, Rönnberg K (1987) Twelwe-year follow-up of caries prevalence and incidence in children and young adults in Espoo, Finland. Community Dent Oral Epidemiol 15: 29-32.

27. Petersen PE, Lennon MA (2004) Effective use of fluorides for the prevention of dental caries in the 21st century: the WHO approach. Community Dent Oral Epidemiol 32: 319-21.

28. American Academy of Pediatric Dentistry (2014) Guideline on Caries-risk Assessment and Management for Infants, Children, and Adolescents. Clinical Practice Guidelines 37: 132-9. 